\title{
Application of digital technology innovation in campus cultural and creative design-Take Jiangxi University of Finance and Economics as an example
}

\author{
Song Pan ${ }^{1, \mathrm{a}}$, Wen Qiang ${ }^{2, \mathrm{~b}}$, Zhang Xiangsen ${ }^{3, \mathrm{c}}$ \\ ${ }^{1}$ School of art of Jiangxi University of Finance and Economics, Nanchang, Jiangxi, China \\ ${ }^{2}$ School of art of Jiangxi University of Finance and Economics, Nanchang, Jiangxi, China \\ ${ }^{3}$ School of art of Jiangxi University of Finance and Economics, Nanchang, Jiangxi, China
}

\begin{abstract}
Absrtact: With the rapid development of information technology and the continuous emergence of artificial intelligence, big data, cloud computing and other advanced technologies, design ushers in a new era of digital technology. The innovative application of digital technology in contemporary design in China promotes the rapid development of cultural and creative design. As an important carrier of university culture, cultural and creative products have become an important part of the construction of university culture, which plays an important role in publicizing the school cultural characteristics and promoting the school brand image. Based on the analysis of excellent campus cultural and creative cases at home and abroad, taking Jiangxi University of Finance and economics as an example, this paper explores the new application of digital technology in contemporary cultural and creative design.
\end{abstract}

\section{Preface}

College culture, also known as "campus culture" or "university culture ", rose in the 1980s. It is the sum of ideological consciousness, moral concept, behavior mode and value goal formed by students as the main body, teachers as the leading body and teachers in the long-term practice of running a university. It is the foundation of university survival, development, running a school and assuming great social responsibility. It has the characteristics of inheritance, pluralism, criticism and vanguard.

\section{Status}

\subsection{Analysis of the domestic situation}

Opportunities and challenges coexist: General Secretary $\mathrm{Xi}$ Jinping put forward the cultural development idea of "strengthening cultural self-confidence and promoting the prosperity of socialist culture" at the Nineteenth National Congress in 2017, which provided fertile soil for the development of Wenchuang products. Looking at the product design of Wenchuang in domestic colleges and universities, the development of cultural and creative industries in Taiwan and a few well-known colleges and universities is relatively perfect. Although most colleges and universities in China have their own Wenchuang products, the Wenchuang industry is basically in its infancy. Products generally face the following problems:

\subsubsection{Design lacks new ideas.}

Most products are stacked in school Logo and simply extracted elements, which were printed on cultural shirts and notebooks. In recent years, some tourists are keen to go to school to play, causing colleges and universities to attach importance to the development of Wenchuang products, but the products do not belong to their own school characteristics, it is difficult to attract tourists, difficult to stand out in a number of college cultural products.

\subsubsection{Cultural connotation is not enough.}

Explore the unique culture of the school (for example: the cherry blossoms of Wuhan University). The designer's understanding of campus culture is not deep enough, most of the products introduced according to their own culture are simple application of elements, and the cultural connotation is insufficient.

\subsubsection{Carrier form is single.}

The products are composed of T-shirt, thermos cup, canvas bag, postcard and other souvenirs, with the same type and single form. 


\subsubsection{Lack of professional team.}

The major of art design in the school can design for the school, but most of them have not been systematically studied and trained, have not set up a special major of cultural and creative products, and the products have not been fully in line with the market.

\subsection{Analysis of the current situation abroad}

The development mode of foreign colleges and universities is more mature, most of them have systematic design, product types are more diverse. Professional R \& D team is responsible for the design, professional factory is responsible for production, to achieve the close cooperation between the school and the market. Based on the basic color of the school, a series of cultural and creative products are designed, which not only get the favor of teachers and students, but also attract the attention of tourists outside school. Cooperation with well-known enterprises not only publicizes the school culture, but also expands the influence and popularity of the brand among teachers and students.

\section{Case analysis and reference}

\subsection{The Coop stores at MIT and Harvard}

The Coop store is an online Wenchuang store opened by MIT and Harvard University. At first, it just sells some stationery, books and other small items. Unlike domestic Wenchuang stores, foreign Wenchuang products are not only sold in schools, but also seen in shopping malls outside school. This shows that foreign Wenchuang products are not only sold to teachers and students in schools, but also to outside school tourists. The Coop store has a wide variety of goods, from sewing to clothing, you can find it in shops. Just a cup can be divided into many kinds according to different styles, materials and functions. The Coop store also has a prominent feature is to cooperate with the enterprise, because of the high popularity of the school itself, it can choose the sun fashion and young brand which is consistent with its own temperament, such as Addidas and Nike. The cooperation between schools and enterprises is a mutually beneficial and win-win process. Enterprises can increase the popularity of young consumers and schools can also bring economic benefits while expanding school consumer groups and creating school brand image. Here is the official website of the The Coop store, as shown in figure 1.

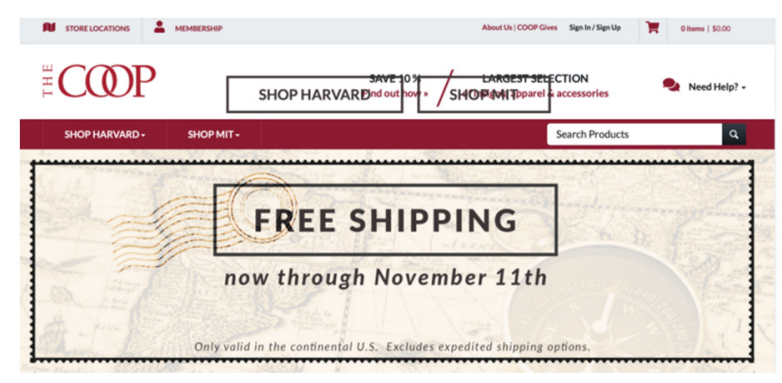

Figure 1 The official website of the The Coop store

\subsection{Hangzhou Normal University}

Hangzhou normal University, located in Hangzhou, capital of Zhejiang Province, is a key construction university in Zhejiang Province organized by Hangzhou Municipal people's Government. In 2018, it created its own cultural and creative brand "HZNU", and opened an online store for teachers and students to buy. Although it has been less than two years since its establishment, the development momentum is good, and the branch of cultural and creative stores has also been developed. Although there is a certain gap between its development scale and the development of foreign universities, it has played a good leading role in the development of cultural and creative stores in domestic colleges and universities. The in-store products are designed by the school graduates authorized by the school officials. The students have a better understanding of the campus culture of Hangzhou normal University and have a certain emotional basis for the school, so that they can better extract the campus elements. The logo of Wenchuang store is the combination of the initials of the school name and the time of building the school, which can be used alone or in combination. The application is more flexible and will change according to the different carriers. School emblem and school motto are also often used in Wenchuang products, the school motto of the elements of diligence, care, sincerity, forgiveness printed on the fisherman's hat, as shown in figure 2; Formed a series of products, highlighted the spiritual and cultural elements of the school, can also in line with the current young people's pursuit of fashion aesthetic taste. Brands fully tap the school's various elements: buildings, scenery and school adorable pet, and so on; Make full use of holiday hot spots, develop a series of products and design mascots on the 110th anniversary of Hangzhou normal University, actively seek business cooperation and raise school popularity, as shown in figure 2; It has greatly improved the recognition degree of HZNU cultural and creative brand among teachers and students, and expanded the brand influence. 


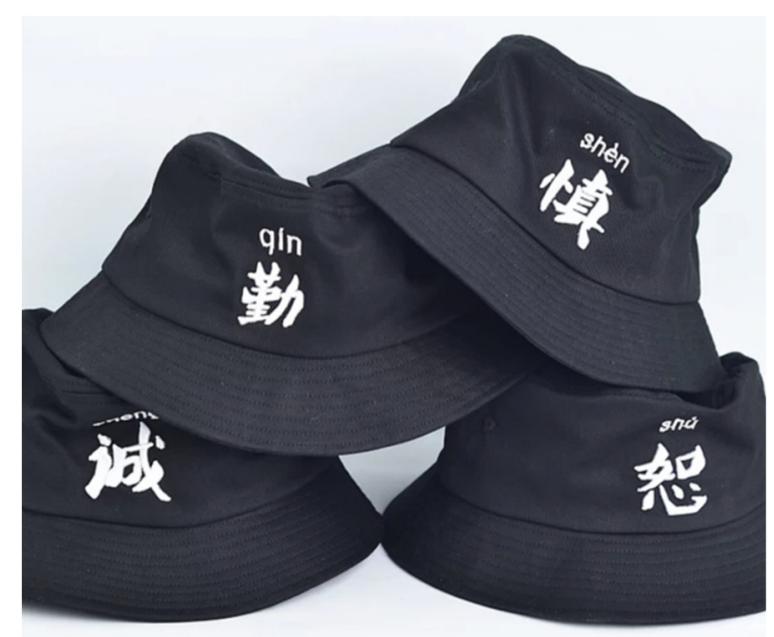

Figure 2 The fisherman's hat

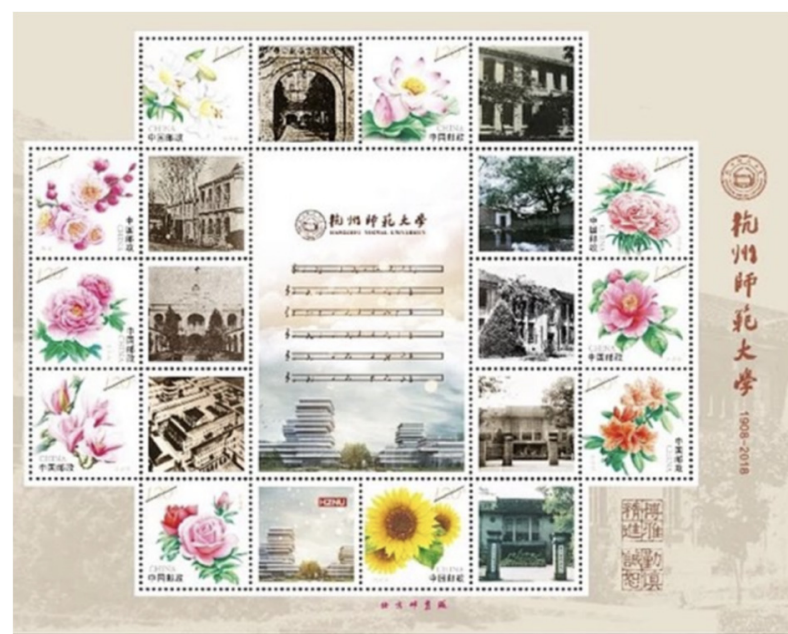

Figure 3 Design mascots on the 110th anniversary

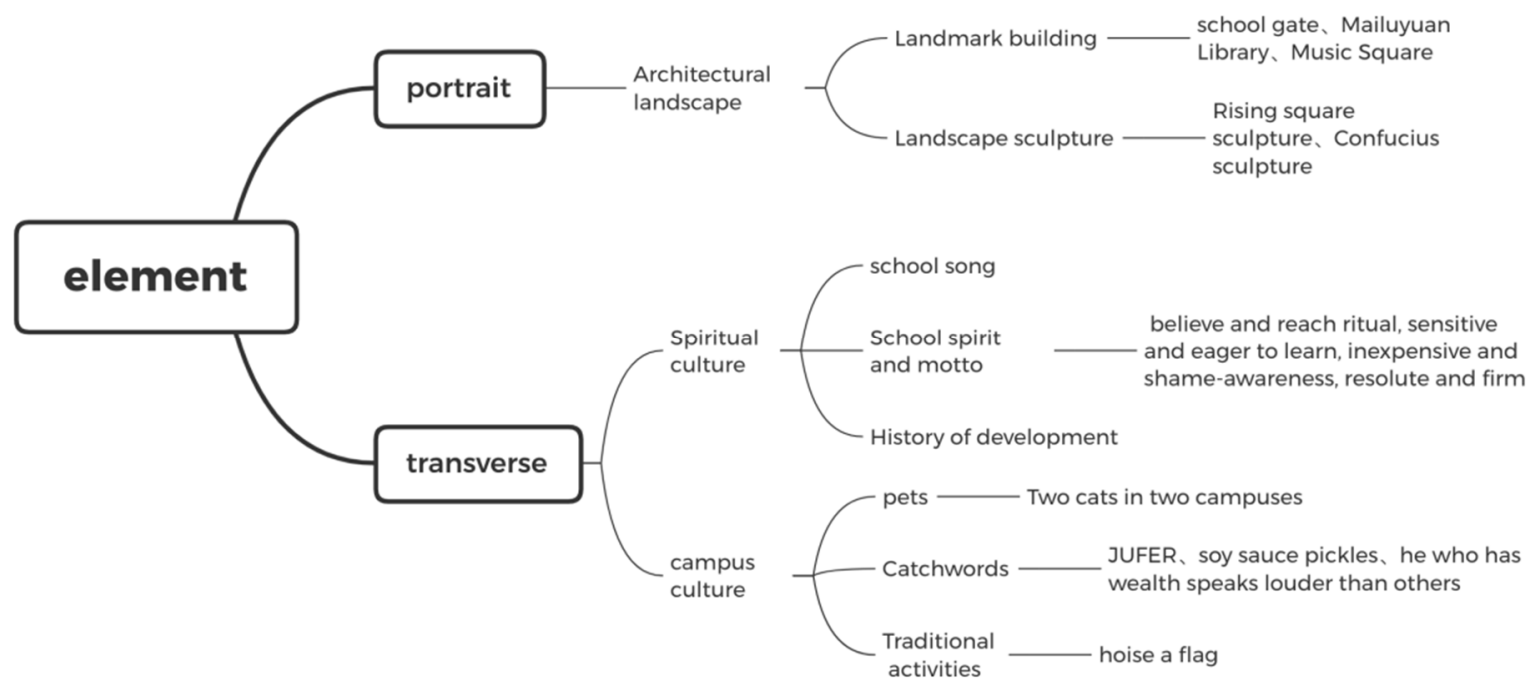

Figure 4 The elements of Jiangxi University of Finance and Economics

\section{Planning and analysis of Wenchuang Product Design of Jiangxi University of Finance and Economics}

Jiangxi University of Finance and Economics is located in Nanchang City, capital of Jiangxi Province. The school was founded in 1923. With rich historical and cultural resources, the school has Jiaoqiao Garden, Mai Lu Garden, Fenglin Garden, Qingshan Garden four campuses, during the Cultural Revolution several times changed its name and was suspended, has a rich and tortuous history of development, is a financial and economic college with its own characteristics. There are many similarities between Jiangxi University of Finance and Economics and Hangzhou normal University, so the development model of Hangzhou normal University has a high reference value for Jiangxi University of Finance and Economics.

\subsection{Refining campus culture elements to products}

Campus culture, as a part of the school, connects the life and memory of teachers and students. Campus cultural creation products show the elements of campus culture in the form of products. The representative cultural elements are extracted and given to the products.

\subsection{Give Wen Chuang product story}

With the progress and development of society, design is not only satisfied with functional needs, people's spiritual requirements are also higher and higher, they hope that design can convey emotion like a story, and the storytelling in the design can enrich the connotation of Wenchuang products through color and graphics, and so on, which can enhance the emotional support between users and products. 


\subsection{Increased value added of products}

Product added value includes aesthetic value, emotional value and brand value, etc. The main purpose is to improve consumer satisfaction with products. In the process of design, we should match culture with products, so as to maximize the added value of products, and the means of increasing the added value of products are various, and brand name is also one of the means to increase the added value of products.

\section{Wenchuang Product Design of Jiangxi University of Finance and Economics}

\subsection{Element analysis and extraction}

The school appearance of Jiangxi University of Finance and Economics is quite characteristic, with wide and majestic gate, tea garden rich in cultural implication, maple garden, Gui garden, as well as the magnificent Jiaoqiao Garden Picture and Text Information Center, which won the National quality Engineering Award of China Construction Project Luban Award in 2018-2019, and the first batch of Jiangxi Province quality Construction Project "Rhododendron Award" in 2019.

Spiritual culture is also impressive in Jiangxi University of Finance and Economics: The lazy cat bask in the sun downstairs in Jinglu every day and the high achiever cat always turn around at the gate of Jiaoqiao Library, each of which occupies a campus and becomes part of Jiangcai's culture. In 1927, the principal of school Luo Jingyuan worked out the motto of "Xin Min Lian Yi ", which means believe and reach ritual, sensitive and eager to learn, inexpensive and shame-awareness, resolute and firm. In the same year, the school song of Jiangxi University of Finance and economics was born with clear and concise words and strong melody.

\subsection{Programmes and presentations:}

Design concept: I extract the key words "no doubt, no worry, no fear, no prostitution, no move, unyielding" from the song, which match with the right font and colors. Then I select the more common Chinese font —_ Song style and the use of a wide range of English font Arial combination presentation; The colors are chosen to match its emotional colors, purple has psychedelic romantic feeling, with no confusion collocation; Don't worry showed with melancholy blue. By printing these elements on the unsophisticated carriers of Wenchuang but indeed on the items _ socks that can not be separated from daily life, showed a feeling of sports fashion that modern young people prefer. The effect diagram is shown in figure 5 :

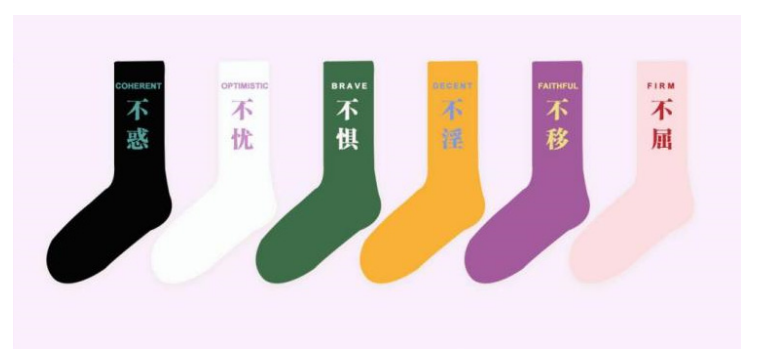

Figure 5 The socks with key words

Another design records the daily things in Jiangxi University of Finance and economics in the form of hand-painted, such as the library of jiaoqiaoyuan, the 520 bus, the gate of the University of Finance and economics, the lazy cat in Jinglu and the sculpture in the rising square. The overall density is carefully arranged to make it look balanced and orderly, there are many elements in the whole. In order to avoid looking messy, the color of black and white monochrome as the overall tone, cable and surface contrast, the overall picture will not be too monotonous, using lovely and interesting painting style, more popular with young people. The carrier selected a large capacity suitable for students canvas bag, which cost lower, but was more suitable for daily use. Satchel front with white as the bottom, the opposite is printed black, echoing the line and surface combination in the illustration, but also increased the level of satchel. The effect diagram is shown in figure 6:

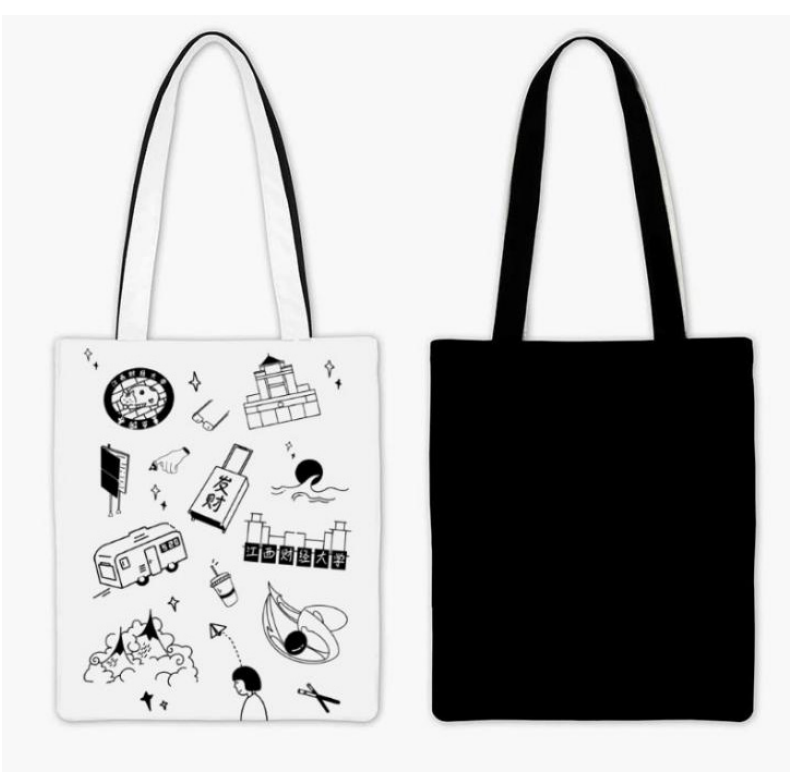

Figure 6 The bag with elements of the campus

\section{Epilogue}

With the continuous development of national economy and the increasing economic level of the people, the development of cultural and creative industries in colleges and universities ushered in a golden period. We should learn from the excellent product development model of foreign and Taiwan universities, learn from their experience, take our own development path, fully explore the elements of campus culture. From school 
buildings to small trees, are the source of inspiration we can play. Use creative techniques to connect design with culture, endow it with emotional value, close the distance from the audience, and improve the image and recognition of Jiang Cai Wen Chuang products in the minds of teachers and students. We should not only embody the characteristics of colleges and universities, but also pay attention to beauty and practicability, and fully show Caida culture. There are some shortcomings in the design and production of this paper, such as the choice of carriers, the diversity of design. Some products can not be put into operation because of some factors. I hope this article can enlighten the design of literary creation in colleges and universities, and also hope to promote the development of cultural and creative industry of Jiangxi University of Finance and Economics.

\section{References}

1. Shang, JY, Dai J, Chen T. (2018) An Analysis of the Cultural Construction of Colleges and Universities. J. Education and Teaching Forum.

2. Zhu, S. (2009) A Study on Regional Cultural Imagery in Modern Product Design. J. Packaging works, 209-210.

3. Baldford. (2017) A Study on the Methods of Product Design Based on Cultural Image. D. Zhejiang University.

4. Zhao, Y. Xiang, XM, Li, J. (2015) Current Situation and Development Prospect of Cultural and Creative Industry. M.and Guangzhou: Guangdong Economic Press.

5. Hao, GC. (2012) Creativity has no standard answer. M.Beijing: Citic Press. 